\title{
Effect of Training Anger-control Skills on Social Adjustment and Anger Self-regulation Skills among High School Students of Khash, Iran in Academic Year of 2009-2010
}

\author{
Maryam Afshari \\ MA in Educational Psychology, Islamic Azad University, Birjand Branch \\ Mona Afshari \\ MA in Educational Psychology, Islamic Azad University, Birjand Branch
}

Doi:10.5901/mjss.2016.v7n3s2p207

\begin{abstract}
The main purpose of this study is to assess the effect of training anger-control skills on social adjustment and anger management of students. To study the effect of anger management training on social adjustment, three schools were selected through cluster sampling and then 200 students (boys and girls) of six classes of high schools in Khash, Iran responded to questionnaire of anger control as a screening tool. Those who gained rank of $75 \%$ and higher based on the scores of this test were determined as students who were not able to control their anger so that they were separated from ordinary population as target group. 30 girls and 30 boys were randomly selected among the target group and divided into two experimental and control groups through random method. Respondent of both groups were evaluated before intervention. Next step included program of training anger management as testing factor or independent variable through 3 months in the form of eight 90minute sessions for 15 members (boys and girls) of experimental group while the members of control group were continuing their ordinary program. After applying the experimental variable, post-intervention evaluations were conducted for members of both girls and boys groups. Co-variance analysis was applied for data analysis and test of means differences was applied to compare means of two independent groups. Pre-test sizes was used as covariate variable in variance analysis and to use $t$ test, differences between pre-test and post-test scores for each of respondents were determined in each of scales and subscales monitoring dependent variables. Then, averages of different scores (D) were compared for each group and test was applied to compare the averages of experimental and control groups. According to the obtained results of this study, experimental interventions have been effective indicating that implementation of training program of anger control has increased adjustment level, reduced anger level in different situations and increased students' skill in field of anger control.
\end{abstract}

\section{Introduction}

Anger of adolescents is an important concern of society because it might lead to some behaviors along with huge damages for economy of countries for instance; ant-social behaviors and violent behaviors are some aspects and consequences of anger. Anger usually continues for long term if it is left untreated (Kendall, 2000).

Many of researchers, clinical experts and educational psychologists have emphasized on the importance of training anger-control skills to children and adolescents. This emphasis has been reflected in current theoretical and applied approaches in field of emotional intelligence, health psychology and applied positive psychology so that these approaches have created a challenge in traditional views about success factors in life, the role of psychologists and groups that need psychological services. Positive psychologists try to facilitate or promote performance of human and this efforts includes an extensive range of human performance (from disorder to health) and different levels of (person, group, organization and community) (LinLey \& Joseph, quoted by Navidi and Borjali, 2007). Comprehensive success of people in life not only is related to intellectual ability but also it requires sufficient qualification in field of anger management (Navidi \& Borjali, 2007). Instead of the clear importance of anger control for experts of health and treatment, but it will be a challenging action to prepare clinical interventions for those who suffer from chronic anger. Persons who suffer from intense anger tend not to be treated; hence, it will be hard to involve them in therapeutic intervention. Adoptive functions of anger as a natural emotion and its relation with symbolic structures such as higher personal, family, and social positions have challenged efforts conducted to progress clinical changes. However, research evidences indicate considerable advances in field of assessment and treatment of persons who suffer from such problems of anger regulation and angry behaviors so that this reality has created the necessity of advanced therapeutic interventions and cover those people who have less anger and harming sources. Therefore, training the anger management as one of the 
main factors of life skills programs is highly beneficial. Anger management training is used as a policy to reduce disadjustment in accordance with interaction between variables of anger and dis-adjustment (Hashemian, 2008). This study has been conducted to assess the effect of training anger-control skills on social adjustment of students (girls and boys) in Khash, Iran in order to determine the effect of training anger-control skills on social adjustment based on gender.

\section{Theoretical Literature}

Emotions are mental, biological, social and purposeful phenomena, inherent phenomena occurring in the same conditions and different persons that are not affected by learning and cultural conditions recalling physiologic personal responses (Rio, Mohammadi Trans, 2004). Emotion have important role in our life.

Anger is one of the complicated human emotions and a common reaction against failure and bad behaviors. All of us have faced different anger-provoking situations in our life. Anger is a natural response of human while it can disturb interactions between people and prevent them from achieving their goals. In fact, anger is a common emotion against friends and relatives who have not met our expectations and needs (Azizi, 2007).

The root of emotion (in English and French languages) is adopted from Latin word of "emovere" that means stimulation and excitement. Emotion would stimulate us and sometimes force us to stimulate ourselves. Sometimes, emotions force us doing or telling something that is not our belief. There are different disagreements on definitions of emotion and different theories have been presented about emotion definitions. These theories are as follows:

\subsection{Behaviorism theory}

According to Tolman, emotion is a tendency or desire toward a special kind of behavior or tendency toward a special kind of effective response to stimulator. According to Skinner, emotion is a special state of ability or weakness in one or several responses created by one action of a set of actions (Dadsetan, 1997).

\subsection{Psychoanalytic theory}

According to Freud, emotions are mentally discharge process that their last state is perceived as the emotion. Rappaport believes that emotions are instinctual conflicts (Dadsetan, 1997).

\subsection{Motivation theory}

According to Yang, emotion is a kind of indignation as a whole with a psychological nature causing behavior, conscious experience and internal changes. William James believes that physical changes are directly obtained from an exciting reality and our feelings at the time of these changes are our emotions (Dadsetan, 1997).

\section{Different Views about Anger Control}

\subsection{Perspective of innate aggressiveness}

Some theorists believe that anger and aggressiveness is instinctive; they have a negative view on anger-control possibility. According to Freud, nothing can be done to prevent aggressiveness of people had wrote, "It is not possible to control aggressive tendencies of people" while there are two suggested methods in this field that are hopeful as follows: one of these theories is international including formation of a set of forces that can control aggressive forces of huge powers and the other one is individual in which, personal conscious can be beneficial as an factor to limit aggressive tendencies that are socially acceptable (exports, negotiations, etc.).

\subsection{Perspective of social learning}

Theorists of social learning are more optimistic about anger control possibility. These theorists also emphasize on nonreinforcement of aggressive responses. Other researchers have suggested following methods in frame of learning theories to control anger (Heidari, 2005). 


\subsection{Reasoning}

This method includes a set of reasoning about dangers and consequences of aggressiveness for aggressive person or criminals of this behavior. This method also can be used to prevent from aggressiveness is persons who are not yet aggressive. For instance, a father might reduce intense anger toward his child if he is informed of possible consequences of aggressive behavior (Heidari, 2005).

\subsection{Aggressive person Punishment}

Punishment of aggressive person might reduce this behavior. It should be explained in this case that hard punishment is not an optimal method because this method is not able to reduce this behavior while light punishment can change the attitude of person toward aggressiveness through preparing external attention for person (Heidari, 2005).

\subsection{Strengthening opposed behaviors}

Strengthening opposed behavior of a bad behavior instead of punishment is a learning principle to remove undesired behavior. If we are about to apply this principle about aggressiveness, we should encourage non-aggressive behavior instead of punishment of aggressive behavior (Rafezi, 2004).

\subsection{Motivational perspective}

Motivational theorists have suggested emotional refining or releasing as a tool to control aggressive behavior. This term was presented by Freud including aggressive energy releasing through aggressive emotions or other alternatives of behavior. They believe that every aggressive behavior is a refining tool that reduces the next aggressive behavior. Proponents of motivational perspective assume that imagination is another way to reduce aggressiveness and anger (Karimi, 1998).

\subsection{Humanistic perspective}

In this perspective, psychotherapists would help patients to have close contact to their real motivations and potential abilities through expressing inner feelings. They believe that people do not show anger when they are free to choose their life method and express their emotions (Ganji, 1996).

\subsection{Cognitive behavioral therapy}

Cognitive behavioral therapy includes two separated psychotherapeutic techniques. These treatments have been used a lot that are considered as a unit treatment. Behavioral therapy of cognition assumes that incorrect and inconsistent thinking patterns would lead to negative emotions and inconsistent behaviors. The basic assumption of cognitive behavioral therapy is that inconsistent behaviors or aggressive emotions are resulted from irrational thinking methods named automated thoughts (Akhoondi, 2001).

\subsection{Context-based social-cognitive model}

Growth of anti-social behavior of adolescents is usually a result of personal and family factors. A part of transformation period is shown along with aggressive behavior of children (Lochman \& velse, 2002, quoted by Safi, 1995). Because this transformational period is related to social environment of child.

According to some conducted studies by Kelz and Berry, 1999, quoted by Navidi, 2008; Fisher, 2004; Pilet, 2002; Breslin, 2005; Macvaugh, 2004; Rise, 2004. Quoted by Navidi, 2008, Allahyari, 1997; Sadeghi, 2001; Tylor and Novaco, 2005, participation in a program of anger-control training can reduce anger level of participants. According to the findings obtained from studies conducted by Bahrami, 2005, quoted by Mohammadkhani, 2005; Hashemian and Shafeeabadi, 2008; Navidi, 2008; Elis et al, 1991, quoted by Mohammadkhani, 2005; Dabous et al, 1994; Hening et al, 1996, quoted by Akhoondi, 2001, training anger-control skills can increase social adjustment of students.

In this regard, this study has assessed the role of training anger-control skills in anger control as well as adjustment level within social, emotional, and educational situations while there have not been any conducted study to investigate the role of anger control in types of adjustment separately. 


\section{Methodology}

This study has assessed the effect of training life skills such as training anger-control skills on social adjustment among students and their self-regulation. It is assumed that the training anger control and promotion of life skills have an effective role in controlling anger and increasing individual and social adjustment of students as well as their anger control.

This study is quasi-experimental with type of pre-test and post-test with control group. Data analysis has been done using Covariance analysis method and t test of different means.

Statistical population of this study includes all male and female high school students of Khash, Iran during academic year of 2009-2010. To determine sample size, three girls and boys schools were chosen among all high schools of Khash and three classes were chosen from each school through multistage cluster sampling (100 female students and 100 male students). Questionnaires of anger control were then distributed among them. Those who gained rank of $75 \%$ and higher based on the scores of this test were determined as students who were not able to control their anger so that they were separated from ordinary population as target group. 30 girls and 30 boys were randomly selected among the target group and divided into two experimental and control groups through random method. The pre-test (social adjustment, anger control) was implemented for all four groups. Then, experimental intervention (training angercontrol skills) was proposed within 8 an hour and a half sessions for experimental groups of girls and boys (30 members) while there was not any intervention in control groups (30 members).

Two main variables of this study include anger control and social adjustment measured and tested with their special measurements.

Reliability of translated questionnaire was reported to $\mathrm{R}=0 / 76$ (Miri, 2009). Rezakhani (1999) has reported reliability of questionnaire equal to 0/75. Alpha coefficients for anger control in this study have been reported above 0/78 indicating high reliability.

Reliability coefficient was determined through three methods described in table 1 (quoted by Karami, 1998).

Table 1. Reliability coefficients of adjustment questionnaire of Sinha and Singh

\begin{tabular}{|l|c|c|c|c|}
\hline Applied method & Emotional & Social & Educational & Total \\
\hline Dividing test & $0 / 94$ & $0 / 93$ & $0 / 96$ & $0 / 95$ \\
\hline Test-retest & $0 / 96$ & $0 / 90$ & $0 / 93$ & $0 / 93$ \\
\hline Kuder Richardson 20 & $0 / 92$ & $0 / 92$ & $0 / 96$ & $0 / 94$ \\
\hline
\end{tabular}

In analysis of questions, coefficients of validity for each question was determined through correlation double-stranded only for questions that their double-standard correlation was confirmed in each of total score and score of each scopes at significance level of 0/001. In addition, Cronbach's alpha was obtained to 80\% (quoted by Karami, 1998).

\section{Findings}

A 200-member sample was chosen through multistage clustering method from high schools of Khash and questionnaires of anger were distributed among them then those students with total score of anger (score of $75 \%$ and above) were chosen and randomly divided into experimental and control groups. Pre-test and post-test was proposed for both groups while training anger-control skills was only presented to experimental group. This part of study includes descriptive and inferential findings.

The obtained results indicated that anger of girls and boys were equal within different personal and family situations while anger level of boys was higher than anger level of girls in social situation. Adjustment of girls was higher than adjustment of boys within three emotional, social and educational fields.

Social adjustment (17/15) was higher than emotional adjustment (16/90) and educational adjustment (15/87) in post-test compared to pre-test. The level of total adjustment of pre-test (before training) was equal to (40/58) and this level was equal to (49/92) after test. As it is observed, total adjustment has been better in post-test and adjustment of girls and boys has been increase in post-test compared to pre-test (separated from experimental and control groups). The anger level of boys was higher than anger level of girls in three types of anger (family, individual and social). Three types of anger in post-test were lower than pre-test. Total anger was lower in post-test. Anger level of boys was more reduced than anger level of girls in post-test (after training) compared to pre-test (before training). 


\section{Hypotheses Assessment}

Hypothesis 1. Training of anger-control skills can effect on increase in social adjustment among male and female students.

The values of two last columns ( $\mathrm{R}^{2}$ and $\mathrm{F}$ ) have been obtained from covariance analysis. All the obtained $\mathrm{F}$ values have been statistically significant indicating that the effect of experimental variable (training anger-control skills) has been significant after removal of pre-test variable (dispersion).

Table 2. Results of Hypothesis 1

\begin{tabular}{|l|l|l|c|c|c|c|c||}
\hline Dependent variable & $\begin{array}{l}\text { Mean difference between } \\
\text { pre-test and post-test of } \\
\text { experimental group }\end{array}$ & $\begin{array}{l}\text { Mean difference between } \\
\text { pre-test and post-test of } \\
\text { control group }\end{array}$ & $\begin{array}{c}\mathbf{t} \\
\text { value }\end{array}$ & $\begin{array}{c}\text { Sig } \\
\text { level }\end{array}$ & $\begin{array}{c}\mathbf{F} \\
\text { value }\end{array}$ & $\mathbf{S i g}$ & $\mathbf{R}^{2}$ \\
\hline \hline Social adjustment of girls & $6 / 8$ & 2 & $5 / 88$ & $0 / 000$ & $15 / 02$ & $0 / 001$ & $0 / 375$ \\
\hline Social adjustment of boys & $7 / 67$ & $1 / 6$ & $5 / 56$ & $0 / 000$ & $22 / 56$ & $0 / 000$ & $0 / 452$ \\
\hline Total social adjustment of the sample & $7 / 23$ & $1 / 8$ & $8 / 13$ & $0 / 000$ & $38 / 74$ & $0 / 000$ & $0 / 405$ \\
\hline
\end{tabular}

According to table 2, the difference between means of pre-test and post-test for girls is obtained to $6 / 8$ in experimental group and to 2 in control group, $t$ value is equal to $5 / 88$ and its significance level is obtained to $0 / 000, F$ value is equal to $15 / 02$ with significance level of 0/001. Hence, it can be concluded that training anger-control skills can effect on increase in social adjustment of female students also training anger-control skills effects on increase in social adjustment of male students. Moreover, training anger-control skills can effect on increase in total social adjustment of students.

$\mathrm{R}^{2}$ values point to the ratio of variance of dependent variable (post-test) that is determined by experimental and covariate variable. It means that $37 \%, 45 \%$ and $40 \%$ of changes in social adjustment of girls, boys and whole sample within after test have been related to the effect of training anger-control skills and pre-test. However, the results of $t$ test and covariance analysis are coordinated and the obtained evidences indicate the effect of educational intervention.

Hypothesis 2. Training anger-control skills can effect on anger control of male and female students.

Anger scores after training considered as dependent variable, anger scores before training considered as dispersion variable, experimental and control group considered as grouping variable.

Table 3. Results of Hypothesis 2

\begin{tabular}{||l|c|c|c|c|c|c|c||}
\hline Dependent variable & $\begin{array}{l}\text { Mean difference between pre-test } \\
\text { and post-test of experimental group }\end{array}$ & $\begin{array}{l}\text { Mean difference between pre-test } \\
\text { and post-test of control group }\end{array}$ & $\begin{array}{c}\mathbf{t} \\
\text { value }\end{array}$ & $\begin{array}{c}\text { Sig } \\
\text { level }\end{array}$ & F value & Sig & $\mathbf{R}^{2}$ \\
\hline \hline Total anger of girls & 13 & $2 / 87$ & $8 / 67$ & $0 / 000$ & $76 / 16$ & $0 / 000$ & $0 / 737$ \\
\hline Total anger of boys & $17 / 33$ & $0 / 6$ & $8 / 91$ & $0 / 000$ & $33 / 24$ & $0 / 000$ & $0 / 552$ \\
\hline $\begin{array}{l}\text { Total anger of the } \\
\text { whole sample }\end{array}$ & $15 / 16$ & $1 / 73$ & $11 / 97$ & $0 / 000$ & $124 / 771$ & $0 / 000$ & $0 / 686$ \\
\hline \hline
\end{tabular}

According to table 3, the difference between means of pre-test and post-test for girls is obtained to 13 in experimental group and to $2 / 78$ in control group, $t$ value is equal to $8 / 67$ and its significance level is obtained to $0 / 000, F$ value is equal to 76/16 with significance level of 0/000 that is lower than 0/05 and as it is observed the results of $t$ test and covariance analysis are coordinated. Hence, it can be concluded that training anger-control skills can effect on anger control in female students also training anger-control skills effects on anger control in male students. Moreover, training angercontrol skills can effect on anger-control of all students. It should be mentioned that $73 \%$ decrease in anger of girls compared to boys (55\%) has been determined by dispersion variable and training anger-control skills.

\section{Other Findings}

First finding. Training anger-control skills effects on motional and educational adjustment of male and female students. 
Table 4. Results of analysis of first finding

\begin{tabular}{|c|c|c|c|c|c|c|c|c|}
\hline \multicolumn{2}{|c|}{ Dependent variable } & $\begin{array}{l}\text { Mean difference between pre- } \\
\text { test and post-test of } \\
\text { experimental group }\end{array}$ & $\begin{array}{l}\text { Mean difference between pre- } \\
\text { test and post-test of control } \\
\text { group }\end{array}$ & $\begin{array}{c}t \\
\text { value }\end{array}$ & $\begin{array}{c}\text { Sig } \\
\text { level }\end{array}$ & $\begin{array}{c}F \\
\text { value }\end{array}$ & Sig & $\mathbf{R}^{2}$ \\
\hline \multirow{3}{*}{$\begin{array}{l}\text { Emotional } \\
\text { adjustment }\end{array}$} & Girls & $2 / 93$ & $0 / 40$ & $7 / 127$ & $0 / 000$ & 56/746 & $0 / 000$ & $0 / 678$ \\
\hline & Boys & $3 / 6$ & $1 / 20$ & $2 / 495$ & $0 / 020$ & $7 / 924$ & $0 / 009$ & $0 / 227$ \\
\hline & Total sample & $3 / 26$ & $0 / 8$ & $4 / 749$ & $0 / 000$ & $30 / 204$ & $0 / 000$ & $0 / 346$ \\
\hline \multirow{3}{*}{$\begin{array}{l}\text { Educational } \\
\text { adjustment }\end{array}$} & Girls & $5 / 54$ & 2 & $4 / 103$ & $0 / 000$ & $17 / 404$ & $0 / 000$ & $0 / 392$ \\
\hline & \begin{tabular}{|l|l|} 
Boys \\
\end{tabular} & $2 / 33$ & $1 / 26$ & $1 / 770$ & $0 / 088$ & $4 / 037$ & $0 / 055$ & $0 / 130$ \\
\hline & Total sample & $3 / 93$ & $1 / 63$ & $3 / 386$ & $0 / 000$ & $14 / 251$ & $0 / 000$ & $0 / 200$ \\
\hline
\end{tabular}

According to table 4, training anger-control skills can effect on emotional adjustment of whole students. The obtained results indicate that $67 \%$ changes in emotional adjustment compared to $39 \%$ changes in educational adjustment have been resulted from training and dispersion variables. $22 \%$ changes in emotional adjustment of boys have been affected by training and dispersion variables that this amount is stronger than educational adjustment. However, emotional adjustment has been determined more than educational adjustment by training anger-control skills and dispersion variable in both boys and girls.

Finally, it is concluded that training anger-control skills can effect on educational adjustment of all students. In total, training and dispersion variables have had the most effect on determining emotional adjustment compared to educational adjustment.

Second finding. Training anger-control skills can effect on reduction in anger level, anger in personal and family relationships as well as social situations in male and female students.

Table 5. Results of analysis of second finding

\begin{tabular}{|c|c|c|c|c|c|c|c|c|}
\hline \multicolumn{2}{|c|}{ Dependent variable } & $\begin{array}{l}\text { Mean difference between pre-test } \\
\text { and post-test of experimental } \\
\text { group }\end{array}$ & $\begin{array}{l}\text { Mean difference between } \\
\text { pre-test and post-test of } \\
\text { control group }\end{array}$ & $\begin{array}{c}t \\
\text { value }\end{array}$ & $\begin{array}{l}\text { Sig } \\
\text { level }\end{array}$ & $\begin{array}{c}F \\
\text { value }\end{array}$ & Sig & $\mathbf{R}^{2}$ \\
\hline \multirow[t]{3}{*}{ Anger level } & Girls & $3 / 87$ & \begin{tabular}{|c|}
$0 / 13$ \\
\end{tabular} & $7 / 164$ & $0 / 000$ & $41 / 466$ & $0 / 000$ & $0 / 606$ \\
\hline & \begin{tabular}{|l|} 
Boys \\
\end{tabular} & $5 / 2$ & $0 / 33$ & $5 / 434$ & $0 / 000$ & $7 / 369$ & $0 / 011$ & $0 / 214$ \\
\hline & Total sample & $4 / 54$ & $0 / 23$ & $8 / 161$ & $0 / 000$ & $35 / 304$ & $0 / 000$ & $0 / 382$ \\
\hline \multirow{3}{*}{$\begin{array}{l}\text { Personal and } \\
\text { family anger }\end{array}$} & Girls & $3 / 33$ & $2 / 2$ & $4 / 137$ & $0 / 000$ & $17 / 796$ & $0 / 000$ & $0 / 397$ \\
\hline & Boys & $6 / 53$ & $0 / 2$ & $5 / 099$ & $0 / 000$ & $19 / 510$ & $0 / 000$ & $0 / 419$ \\
\hline & Total sample & $4 / 94$ & $1 / 2$ & $6 / 210$ & $0 / 000$ & $47 / 704$ & $0 / 000$ & $0 / 456$ \\
\hline \multirow[t]{3}{*}{ Social anger } & Girls & $5 / 8$ & $0 / 53$ & $7 / 753$ & $0 / 000$ & $56 / 788$ & $0 / 000$ & $0 / 678$ \\
\hline & Boys & $5 / 6$ & $0 / 07$ & $6 / 531$ & $0 / 000$ & $26 / 638$ & $0 / 000$ & $0 / 497$ \\
\hline & Total sample & $5 / 7$ & $0 / 3$ & $10 / 454$ & $0 / 000$ & $91 / 602$ & $0 / 000$ & $0 / 616$ \\
\hline
\end{tabular}

According to table 5, training anger -control skills effects on reduction in anger level of all students. It was concluded that training anger -control skills effects on reducing anger in personal and family relationships among female students also training anger -control skills effects on reducing anger in personal and family relationships among male students.

Training anger-control skills and dispersion variable have had the more effect on reducing anger in social situation of girls (67\%) compared to boys (55\%) also control training and dispersion variable have had the most effect on determining anger in social situations (67\% and 49\%) than anger level and anger in personal and family relationships.

The obtained results indicate that training anger-control skills and dispersion variable have had the most effect on reduction in total anger within social situations (61\%) compared to anger level (38\%) and anger in personal and family relationships (45\%).

Training of anger control and dispersion variable have had the lowest effect on determining anger in personal and family relationships among girls (39\%) and have had the lowest effect on determining anger level among boys (21\%).

\section{Discussion and Conclusion}

In all interventions of anger control, it is emphasized on adjustment of severity, duration, frequency, experience and expression of anger along with facilitating non-violent and community-friendly responses to interpersonal relationships 
(Findler, 2005). Intervention program of Klinke (1998) was applied in this study to prepare a special program for training anger control during three months within 8 sessions for members of experimental group. This intervention program includes three behavioral, cognitive and physiologic aspects. It has been emphasized on preventing from anger, adjustment and emotional provocation, controlling responses toward anger stimulating situations, appropriate expression of anger through training skills to adjust emotional provocation and promotion of social skills during training period. Therefore, it is expected that participant cam correct their distorted recognitions (documents, expectations, interpretations and beliefs) using strategies of calming to adjust frequency, intensity and duration of physiologic provocation, to enrich their social behavior and to be able react through an adoptive method when facing anger stimulating situations. Participants are trained to adjust different aspects of anger including components of anger experience, anger stimulators, consequences of anger incidents, etc. in order to adopt anger with its behavioral, cognitive and physiologic aspects when responding to interpersonal conflicts using problem solving strategies and other adoptive strategies.

Three factors of applied intervention are based on psychological approaches. Perspective of Zilmann about physiological factor is remarkable. Key discovering of Zilmann about "effects of Excitation-transfer" (1971, quoted by Tylor and Novaco, 2005) indicated that an obtained excitation from previous event could be combined with next excitations. It means that if excitation is not discharged, it can be transferred to current events intensifying anger experience along with increasing anger capacity for aggressive behavior.

There are some researches and theories about cognitive factor presented by Lazarus, Glass and Singer (1972, quoted by Tylor and Novaco, 2005) have considered the concept of mediator role of cognitive factor so that the main core of study about anger and cognitive-behavioral interventions includes this factor (Tylor \& Novaco, 2005). Some pioneers of cognitive-behavioral approach especially Meichenbaum (1977) has considered mediator role of cognitive factor as the base of anger treatment and immunity against stress (Meichenbaum \& Novaco, 1978, quoted by Tylor and Novaco, 2005).

According to the mentioned points, it can be stated that relevant psycho-educational interventions to anger have generally behavioral-cognitive nature. A treatment based on behavioral-cognitive approach is a combination of cognitive and behavioral approaches. In this type of treatment, patient is able to identify distorted thinking patterns and inconsistent behavior through regular discussions and organized behavioral tasks. Some aspects of treatment have emphasized on behavioral factor and other aspects on cognitive factors. Therefore, emphasis of treatment prepares an opportunity for new adoptive learning and changes in outside space of clinical environment. Problem evolvement is the most important component of treatment (Ghasemzadeh, 2006).

The obtained findings of this study indicated that interaction between this kind of psycho-educational interventions over anger control and social-cultural conditions of Iran have been positive.

According to the results of hypothesis 1 , the effect of training anger-control skills on increase in social adjustment among male and female students.

The obtained results of conducted study by Navidi (2008) indicated that implementation of training program for anger control can expand adjustment skills and reduce their inconsistencies. The study conducted by Hashemian and Shafeeabadi (2008) indicated that anger-control skills is effective in increased adjustment among high school students. According to the obtained results of conducted studies about by Elis et al (1991, quoted by Mohammadkhani, 2005) and Giner et al (1993, quated by Mohammadkhani, 2005) about effectiveness of training life skills, participants in programs have been faced fewer social problems compared to control group.

Other findings of this study indicated that not only social adjustment but also emotional and educational adjustments (except boys) of students were increased. Although the effect of intervention on increase in emotional adjustment has been significant before test, but there has not been any study to separately assess changes in types of adjustment while this study obtained this result.

The effect of training anger control on boys was not significant. According to study of Dabous et al (1994), there is a significant relationship between family structure, relationship between parents and adjustment of students in school. Therefore, it can be understood that family function and parents' relationships have been the most important and effective factors in educational adjustment, these variables might have a mediator role so that they have not been assessed in this study. The other probability is cultural context of patriarchy of studied population because family factor is effective in educational adjustment so that there has not been a significant increase in educational adjustment in this study in effect of training anger control without any attention to the effect of cultural and family context on this variable.

According to the results of hypothesis 2, the effect of training anger-control skills was significant on anger control among male and female students. There have been many studies in this field. Navidi and Borjali (2007) indicated that skills of participants in field of anger management were increased affected by implementation of program of anger management. Findler and Weisner (2005) have pointed many studies in which, the effect of psycho-educational 
interventions on anger management was significant within target groups and different environments.

Kelz and Berry (1999) implemented educational program of anger management for 7 students of a school that were emotionally distracted and they indicated some positive effects; hence, their results are coordinated with obtained results of present study. Sakhodelski et al (2000, quoted by Findler and Weisner, 2005) conducted a study to evaluate the effectiveness of a 10-sessions educational program in which, intervention program had a behavioral-cognitive nature concentrating on increase in emotional awareness, recognition of provoking signs, improvement of supervision, anger control and reconstruction of documents.

According to the results of secondary findings of this study, effect of training on anger reduction in different situations (anger level, personal, family and social situations) was significant.

The obtained results of this study indicated that in effect of training anger control, anger in social situations had more reduction than anger level and anger in family and personal relationships had more reduction among boys and girls; of course, this result was more among girls.

Pilet (2002) studied the effect of training anger management on reduction in family violence using experimental and control groups. He concluded that participation in 8-sessions program of anger management could reduce anger level of members of experimental group. Breslin (2005) investigated the effectiveness of program of anger management on prevention from family violence commitment and concluded that there was a relationship between participating in program of anger management and reduction in family violence commitment. Macvaugh (2004) came to this conclusion that participation in program of anger management could reduce family violence commitment.

Contrary to the obtained results from mentioned studies, it can be understand from results of present study that although anger level among boys and anger in personal and family relationships have been significant, but they have had the lowest reduction in effect of training. However, the lower effectiveness of training on anger level among boys might be related to gender differences. Nevertheless, training anger control had a significant effect on boys and girls. It should be mentioned that conducted studies by Breslin (2004), Macvaugh (2004) and Pilet (2004) do not include comparison between reduced family anger and other situations while this study has compared different anger stimulating situations and obtained mentioned results; hence, the more clear results will be obtained if various studies carry out in different communities with different cultural contexts.

\section{References}

Breslin, J.H. (2005). Effectiveness of a rural anger management program in preventing domestic violence recidivism. Joyrnal of school psychology, vol, 13, P.1715

Dubois, DI \& Filner, RP. (1994), Effects of family environment during the transition family early adolescence, Journal of marriag and the family, Vol 56

Feindler, E.L. \& Weisner, S. (2005) Youth anger management treatment for school violence prevention. Unpublished manuscript (in press)

Kendall, p.c. (2000), Child and adolescent therapy: cognitive behavioural procedures (2 nd ed). New York: Guilford

Macvaugh, G.S. (2004). Outcomes of court intervention and disversionary programs fpr domestically violence offenders. Joyrnal of school psychology, P.6(3): 159-162

Navaco, R. W. (1985). Stress inoculaton therapy for anger control: A manual for tjerapists. Unpublished manuscript Journal of school psychology, P: 168-189

Novaco, R. W. \& Chemtob, c. m., (1998), Anger and trauma: Conceptualization, assessment, and treatment, In: Follette, V.H. Ruzek, V.I. \& Abueg, F.R.Cognitive-Behavioral Therapies for Ttauma New York: Guolynd

Pilet, G.A. (2002). Efficacy of adult psychoeducation in an anger management portion of a domestic violence treatment program. University of California Irvive, vol. 34, 136

Taylor, j.L., Navaco, R.w., (2005) cognitive-behavioral treatment of anger vntensity among offenders with ivtellevtual disabilities, Journal of Applied Reserch in Intellectual Disabilities, 15, 151-165

Akhoondi, Z. (2001), The effects of group cognitive - behavioral therapy of anxiety Islamic secondary school students in the city, a Master's thesis General Psychology, Faculty of Psychology and Educational Sciences, Allameh Tabatabaei

Allahyari, A. (1997), determine aggression by personality traits and the relationship between these components and the level of fathers' personality traits and aggression with aggression, the effect of de-stress therapy. PhD thesis, Tehran, Tarbiat Modarres University, Humanities, Department of Psychology

Heydari, A., (2005), examine the relationship between family function and egoism components in the grade two male high school students of Ilam, MA Thesis

Dadsetan, P., (1997), psychology of morbid changes, Tehran, SAMT Pub

Rafezi, Z., (2004), The role of anger control training in adolescents 15 to 18 years old on aggression, Master's Thesis

Sadeghi, A., (2001), examine the effectiveness of anger control training, rational manner, behavioral, emotional reducing aggressive behavior of male high school students, Master's thesis, Isfahan, Isfahan University, Faculty of Education and Psychology 
Safi, A., (2005), Balancing family, parents and educators Publications, Third Edition

Azizi, B., (2007), examine the relationship between family functioning and social popularity teens in peer groups, MS Thesis, Islamic Azad University Roodehen Branch

Ghasemzadeh, H., Motarjem, (2006), Cognitive Behavior Therapy: A Practical Guide for the treatment of Mental Disorders (Houghton wrote, crack, Salkvvs case, Clark, 1989). Fifth Edition, Tehran, ARJMAND Pub

Karimi, y., (1998), Social Psychology, Fourth Edition, Tehran: Arasbaran Pub

Karami, A., (1998), family functioning and coping with stress, Master Thesis, University of Allameh Tabatabai

Ganji, H., (1996), General Psychology, Tehran, publisher of Payam Noor

Mohammadkhani, S., (2005), Life Skills, Fourth Edition, SAMT Pub

Navidi, B., (2007), The effects of implementing a program of anger management training on anger self-regulation skills of male high school students, psychological research Issues $3 \& 4$, Pp. 58-72

Hashemian, F., Shafiabadi, A., (2008), Efficacy of training anger control skills on socio-personal adjustment of the junior high school girl students, City of Mahshahr, Journal of Knowledge and Research in Psychology, Islamic Azad University Khorasgan, Branch, Issues 35 \& 36, Pp. 1-14 